\title{
Long-Term Effect of Gastric Bypass and Sleeve Gastrectomy on Severe Obesity : Do Preoperative Weight Loss and Binge Eating Behavior Predict the Outcome of Bariatric Surgery?
}

Pekkarinen, Tuula 2016-09

Pekkarinen, T , Mustonen , H , Sane , T , Jaser , N , Juuti , A \& Leivonen , M 2016 , ' Long-Term Effect of Gastric Bypass and Sleeve Gastrectomy on Severe Obesity : Do Preoperative Weight Loss and Binge Eating Behavior Predict the Outcome of Bariatric Surgery? ' , Obesity Surgery , vol. 26 , no. 9 , pp. 2161-2167 . https://doi.org/10.1007/s11695-016-2090-7

http://hdl.handle.net/10138/224128

https://doi.org/10.1007/s11695-016-2090-7

publishedVersion

Downloaded from Helda, University of Helsinki institutional repository.

This is an electronic reprint of the original article.

This reprint may differ from the original in pagination and typographic detail.

Please cite the original version. 


\title{
Long-Term Effect of Gastric Bypass and Sleeve Gastrectomy on Severe Obesity: Do Preoperative Weight Loss and Binge Eating Behavior Predict the Outcome of Bariatric Surgery?
}

\author{
Tuula Pekkarinen $^{1}$ • Harri Mustonen ${ }^{2}$ - Timo Sane ${ }^{3}$ - Nabil Jaser ${ }^{1}$ • Anne Juuti ${ }^{1}$. \\ Marja Leivonen ${ }^{1}$
}

Published online: 3 February 2016

(C) Springer Science+Business Media New York 2016

\begin{abstract}
Background Few studies have examined weight loss sustainability after sleeve gastrectomy (SG). The purpose of this study was to determine long-term outcome after SG and gastric bypass (GBP) and learn whether preoperative weight loss and binge eating behavior can be used to predict outcome. Materials and Methods Together, 257 patients (64 \% women) were operated, 163 by GBP and 94 by SG. Binge eating was assessed by binge eating scale (BES) and preoperative weight loss was advised to all, including very low-calorie diet for 5 weeks. Postoperative visits took place at 1 and 2 years, and long-term outcome was at median 5 years (range 2.29-
\end{abstract}

Tuula Pekkarinen

tuula.pekkarinen@hus.fi

Harri Mustonen

harri.mustonen@helsinki.fi

Timo Sane

timo.sane@kolumbus.fi

Nabil Jaser

nabil.jaser@hus.fi

Anne Juuti

anne.juuti@hus.fi

Marja Leivonen

marja.leivonen@epshp.fi

1 Abdominal Center, Peijas Hospital, Helsinki University Hospital, P.O. Box 900, FIN-00029 HUS Vantaa, Finland

2 University of Helsinki and Helsinki University Hospital, P.O. Box 440, FIN-00029 HUS Helsinki, Finland

3 Abdominal Center, Meilahti Hospital, Helsinki University Hospital, P.O. Box 340, FIN-00029 HUS Helsinki, Finland
6.85). Multivariate linear regression analysis was used to predict outcome at 2-year and long-term control.

Results Median age was 48 years, weight $141.1 \mathrm{~kg}$, and BMI $48.2 \mathrm{~kg} / \mathrm{m}^{2}$. Preoperative weight loss was median $4.9 \%$ before GBP and $3.8 \%$ before SG, $P=0.04$. Total weight loss at year one was $24.1 \%$ in GBP and $23.7 \%$ in SG $(P=0.40)$, at year two 24.4 and $23.4 \%(P=0.26)$, and at long-term control 23.0 and $20.2 \%(P=0.006)$, respectively. Weight was analyzed in 93,88 , and $89 \%$ of those alive, respectively. BES did not predict weight outcome, but larger preoperative weight loss predicted less postoperative weight loss at 2 years.

Conclusion On long term, weight loss was better maintained after GBP compared with SG. Binge eating behavior was not a significant predictor, but larger preoperative weight loss predicted less postoperative weight loss for the next 2 years.

Keywords Sleeve gastrectomy · Gastric bypass · Long-term outcome $\cdot$ Predictors

\section{Introduction}

Together with the global obesity epidemic, incidence of morbid obesity has increased progressively during the past decades [1,2] and forecast suggests further increase [3]. At present, based on the achieved amount of weight loss with favorable effects on co-morbidities [4, 5] and quality of life [6], expert guidelines recommend bariatric surgery as the most effective therapy for morbidly obese patients.

These same data, however, show poorly sustained weight loss especially after vertical banded gastroplasty and gastric band [4]. These operations have been replaced by sleeve gastrectomy (SG) which has shown comparable initial weight loss as gastric bypass (GBP). Yet, data of long-term weight loss maintenance after SG are limited [7]. Furthermore, only 
29 of 1136 bariatric studies have reported long-term follow-up reliably, i.e., over 2 years with $80 \%$ retention rate [7]. As nonresponders to any therapy of obesity are known to be most likely lost to follow-up, the estimates of efficacy of bariatric surgery may be positively biased overall. Reliable long-term follow-up studies are still needed.

Suboptimal weight loss after bariatric surgery has been related to non-surgical rather than to surgical factors. Given the high number of reports that have been published in this field, surprisingly little is known of factors predicting postoperative weight loss [8]. Binge eating behavior, a relatively common condition among surgery candidates, has been associated with both impaired [9-11] and improved [12-14] weight loss after bariatric surgery, while others have not found any relationship [15]. Although binge eating is not a contraindication to bariatric surgery, assessment of binge eating preoperatively has been suggested [16] and clinicians may still hesitate whether surgery is suitable for bingers. To find predictors of favorable outcome, preoperative weight loss has also been studied with highly inconsistent findings [8].

The purpose of this study is to compare short- and longterm weight losses after laparoscopic GBP and SG. In addition, we examined the role of binge eating behavior and preoperative weight loss as predictors of treatment response.

\section{Methods}

\section{Study Design and Patients}

Screening The bariatric unit at Peijas Hospital, Helsinki University Hospital, initiated December 2007, and by the end of 2009, had performed 264 operations in 262 patients. Of them, 163 underwent laparoscopic GBP and 94 laparoscopic SG, and the results of these 257 patients are reported here. In addition, one patient underwent duodenal switch, four removal of previously inserted gastric band, and two initial SG converted soon to GBP according to a preoperative plan.

The patients were referred for bariatric surgery from primary and occupational health care and were screened by endocrinologist and bariatric surgeon. Criteria were BMI $>40$ without or $>35 \mathrm{~kg} / \mathrm{m}^{2}$ with comorbidity, age $<65$ years at the time of consultation, and previous participation in a conservative weight reduction program without sustained weight loss, motivation toward, and understanding of the risks of bariatric operation and eating limitations postoperatively. The contraindications, defined by interview and medical history, were current severe psychiatric problem/bulimia nervosa or drug/ alcohol abuse and severe cardiopulmonary disease.

The initial appointment with the endocrinologist included physical examination, medical history, laboratory evaluation, and assessment of binge eating and was followed by screening by surgeon. Preparation for surgery included preoperative and postoperative nutrition education. Patients were instructed to start 5 weeks prior surgery a very low-calorie $\operatorname{diet}$ (VLCD) as only food. These commercially available diets provide 52 $58 \mathrm{~g}$ of protein; $52-64 \mathrm{~g}$ of carbohydrates; $8-13 \mathrm{~g}$ of fat and daily requirements of vitamins, trace elements, and minerals; and daily energy intake of 2200-2340 kJ.

Perioperative and postoperative phases All procedures were performed as previously prescribed [17] by three surgeons (ML, NJ, and AJ). The type of bariatric surgery was chosen by the surgeon with the patient's agreement. GBP was the operation of choice. SG was chosen for those with impaired respiratory capacity, incipient liver cirrhosis, coagulopathy, inflammatory bowel disease, severe intra-abdominal adhesions, $\mathrm{BMI}>60 \mathrm{~kg} / \mathrm{m}^{2}$, age $>60$ years, permanent need for NSAIDs, or patient's preference. Surgical method was randomized among few patients, since they participated in a multicenter study comparing GBP and SG [17]. All patients received standard dietary instructions preoperatively and postoperatively.

Appointments with endocrinologist were at 3 months, year one, and year two. Long-term follow-up data was collected by the end of year 2014. Weights were collected retrospectively from medical records. If not available, we asked weight by phone.

\section{Measurements}

Weight was measured with light clothing and no shoes using a digital scale with an accuracy of $0.1 \mathrm{~kg}$ at initial visit with endocrinologist (baseline weight), in the morning of the operation (operation weight), at 1- and 2-year control with the endocrinologist. Long-term weight was collected from medical records. There were four pregnancies postoperatively (2.3, $2.6,4$, and 5 years after surgery). Weight prior pregnancy was used as long-term weight. If no measured weight was available, we asked current weight by phone and $2 \mathrm{~kg}$ was added to self-reported weight [18].

To identify binge eating behavior, a self-rated questionnaire, the binge eating scale (BES) was used [19]. The BES has been developed to assess binge eating problem in the obese. In clinical practice, a cutoff, little or no problem score, is 17 , moderate bingers score from 18 to 26 , and patients with serious problems score 27 or more.

\section{Statistics}

Results are given as median and ranges or number of patients and percentages. Preoperative weight loss was calculated baseline weight-operation weight. Weight change was calculated as total weight loss percent (\%TWL) (weight change/baseline or operation 
weight) $\times 100$, as BMI change (current BMI baseline or operation $\mathrm{BMI}$ ) and as percent excess weight loss (\%EWL). This was calculated as current weight-BMI 25 weight $=$ excess body weight, percent excess weight loss $=($ current excess weight/baseline or operation excess weight $) \times 100$. Linear regression analysis with bootstrapping (1000 samples) was used to find out significant factors and covariates affecting weight loss percent at 2-year and at long-term control. In multivariable analysis age (dichotomized at 45 years), comorbidity, operation type, preoperative weight loss, and baseline BMI were included into the model. The exact KolmogorovSmirnov test was used to assess the normality of continuous variables. The continuous variables included into the linear regression analysis were normally distributed. Twosided $P$ values were used. $P$ values $<0.05$ were considered statistically significant. Data was analyzed with IBM SPSS software (v22, IBM Corporation, NY).

\section{Results}

The baseline characteristics are given in Table 1 . The median age was 48 years, weight $141.1 \mathrm{~kg}$, BMI $48.2 \mathrm{~kg} / \mathrm{m}^{2}$, all were Caucasians, and $64 \%$ women. Preoperatively, median weight loss was $4.9 \%$ (range $9.6 \%$ gain to $18.0 \%$ loss) for those undergoing GBP and $3.8 \%$ (range $8.7 \%$ gain to $37.3 \%$ loss) for those undergoing $\mathrm{SG}, P=0.04$ between groups.
Median long-term follow-up was 5.0 years (range 2.3-6.9), 5.0 years (range 2.4-6.6) for GBP, and 4.8 years (range 2.36.9) for $\mathrm{SG}, P=0.12$ between the interventions.

Attrition Together, 20 patients did not attend 1-year control. Two of them had died, a 53-year-old man 7 months, and a 42-year-old man 8 months after SG. At 2-year control, 34 were not contacted; one of them was a 59-year-old woman with SG who had died in septicemia. Thus, of those alive, $93 \%(237 / 255)$ attended 1-year and $88 \%$ (223/254) 2-year control. At long-term follow-up, weight of 28 patients was not available. Eight of them had died after 2-year control, a 65-year-old man (incarcerated hernia and peritonitis) and a 51-year-old woman after SG. After GBP, a 66-year-old man (carcinoma), a 51-yearold man, a 59-year-old woman (lymphoma and cirrhosis of liver), a 58-year-old man (alcohol abuse), a 57-year-old man, and a 36-year-old woman had died. Taken together, 11 (4\%) patients had died during the follow-up. Of the 246 patients alive, weight data of 218 (89\%) was collected from hospital records or was reported $(41 \%)$ by phone median 5 years after operation. Of the GB patients, 61 (45\%), and of the SG patients, 30 (37\%), self-reported their weights.

Weight loss data are shown in Table 2 and Fig. 1. At 1-year control, median weight loss was $24.1 \%$ of baseline weight in the GBP group and $23.7 \%$ in the SG group, $P=0.40$. At 1 year control, weight loss was less than $10 \%$ from baseline
Table 1 Baseline characteristics of the patients, data are median (range) or $n(\%)$

\begin{tabular}{|c|c|c|c|c|}
\hline & All $(n=257)$ & $\begin{array}{l}\text { Gastric bypass } \\
(n=163)\end{array}$ & $\begin{array}{l}\text { Sleeve gastrectomy } \\
(n=94)\end{array}$ & $\begin{array}{l}P \text { between } \\
\text { groups }\end{array}$ \\
\hline Age, years & $48.0(24-67)$ & $47.0(24-63)$ & $49.0(24-67)$ & 0.31 \\
\hline Female & $165(64)$ & $102(63)$ & $63(67)$ & 0.50 \\
\hline Working & $196(78)$ & $127(80)$ & $69(76)$ & 0.52 \\
\hline Weight, kg & $141.1(96.2-230.0)$ & $144.3(92.6-205.2)$ & $131.1(101.1-230.0)$ & 0.06 \\
\hline BMI, $\mathrm{kg} / \mathrm{m}^{2}$ & $48.2(36.8-77.1)$ & $49.2(38.7-68.21)$ & $47.4(36.8-77.1)$ & 0.46 \\
\hline BES score $^{a}$ & $12(0-38)$ & $13(0-36)$ & $11(0-38)$ & 0.15 \\
\hline \multicolumn{5}{|l|}{ Medical condition } \\
\hline Type 2 diabetes ${ }^{\mathrm{b}}$ & $108(42)$ & $68(42)$ & $40(43)$ & 0.90 \\
\hline Hypertension $^{\mathrm{c}}$ & $172(67)$ & $109(67)$ & $63(67)$ & 1.0 \\
\hline Sleep apneoa ${ }^{\mathrm{d}}$ & $72(28)$ & $45(28)$ & $27(29)$ & 0.89 \\
\hline Knee/ankle arthrosis ${ }^{\mathrm{e}}$ & $85(33)$ & $59(36)$ & $26(28)$ & 0.17 \\
\hline Psychiatric disorder ${ }^{\mathrm{f}}$ & $56(22)$ & $38(23)$ & $18(19)$ & 0.60 \\
\hline
\end{tabular}

${ }^{\text {a }}$ Binge eating scale, $n=221$ for all ( $n=142$ in gastric bypass and $n=79$ in sleeve gastrectomy)

${ }^{\mathrm{b}}$ Defined as a history of type 2 diabetes, a fasting glucose concentration of $7.0 \mathrm{mmol} / \mathrm{l}$ or more, or a use of glucose-lowering medication

${ }^{\mathrm{c}}$ Defined as a history of hypertension or use of antihypertensive medication

${ }^{\mathrm{d}}$ Defined as a history of diagnosed sleep apnoea

${ }^{\mathrm{e}}$ Defined as a history of arthrosis of knee or ankle

${ }^{\mathrm{f}}$ Defined as a history of previously diagnosed psychiatric disorder 
Table 2 Median (ranges) changes in BMI, total weight loss percentage (\%TWL), and extra weight loss percentage $(\% \mathrm{EWL})$ from baseline and from operation in all and in both operations

\begin{tabular}{|c|c|c|c|c|}
\hline & All & Gastric bypass & Sleeve gastrectomy & $\begin{array}{l}P \text { between } \\
\text { operations }\end{array}$ \\
\hline \multicolumn{5}{|c|}{$\Delta \mathrm{BMI}$ from baseline } \\
\hline Year 1 & $12.0(0.8-29.8)$ & $12.1(1.6-24.0)$ & $11.3(0.8-29.8)$ & 0.37 \\
\hline Year 2 & $11.8(-3.0-30.2)$ & $12.0(1.7-28.4)$ & $10.8(-3.0-30.2)$ & 0.19 \\
\hline Long term & $10.5(-2.7-32.6)$ & $11.6(-2.7-32.6)$ & $9.2(-1.2-27.8)$ & 0.002 \\
\hline \multicolumn{5}{|c|}{$\Delta \mathrm{BMI}$ from operation } \\
\hline Year 1 & $9.4(-1.4-19.7)$ & $9.4(1.4-19.7)$ & $9.5(-1.4-18.9)$ & 0.68 \\
\hline Year 2 & $9.4(-2.5-23.8)$ & $9.8(1.2-23.8)$ & $8.2(-2.5-23.8)$ & 0.23 \\
\hline Long term & $8.0(-6.3-26.6)$ & $8.8(-6.3-26.6)$ & $7.0(0.1-23.3)$ & 0.003 \\
\hline \multicolumn{5}{|c|}{$\%$ TWL from baseline } \\
\hline Year 1 & $23.9(1.8-43.2)$ & $24.1(4.1-43.0)$ & $23.7(1.8-43.2)$ & 0.40 \\
\hline Year 2 & $23.9(-7.1-53.0)$ & $24.4(4.2-50.7)$ & $23.4(-7.1-53.0)$ & 0.26 \\
\hline Long term & $21.5(-5.9-53.6)$ & $23.0(-5.9-53.6)$ & $20.2(-2.5-49.6)$ & 0.006 \\
\hline \multicolumn{5}{|c|}{$\%$ TWL from operation } \\
\hline Year 1 & $20.1(-3.3-39.3)$ & $20.3(3.4-39.3)$ & $19.9(-3.3-37.8)$ & 0.57 \\
\hline Year 2 & $19.5(-5.7-48.7)$ & $20.1(2.9-47.3)$ & $17.8(-5.7-48.7)$ & 0.19 \\
\hline Long term & $17.7(-14.9-48.5)$ & $19.1(-14.9-48.5)$ & $15.2(0.2-47.1)$ & 0.007 \\
\hline \multicolumn{5}{|c|}{$\%$ EWL from baseline } \\
\hline Year 1 & $49.3(4.2-100.6)$ & $49.5(11.3-100.6)$ & $48.7(4.2-94.7)$ & 0.16 \\
\hline Year 2 & $49.0(-17.0-117.0)$ & $49.0(11.7-104.5)$ & $49.0(-17.0-117.0)$ & 0.46 \\
\hline Long term & $44.7(-13.0-109.4)$ & $46.9(-13.0-107.0)$ & $43.0(-5.2-109.4)$ & 0.03 \\
\hline \multicolumn{5}{|c|}{$\%$ EWL from operation } \\
\hline Year 1 & $44.7(-8.2-100.9)$ & $44.7(8.2-100.9)$ & $44.5(-8.2-92.8)$ & 0.72 \\
\hline Year 2 & $42.8(-15.0-120.8)$ & $43.1(7.6-105.7)$ & $40.7(-15.0-120.8)$ & 0.24 \\
\hline Long term & $39.9(-36.7-111.6)$ & $42.1(36.7-108.8)$ & $35.3(0.5-111.6)$ & 0.03 \\
\hline
\end{tabular}

All patients $n=237$ year $1, n=223$ year 2, $n=218$ at long-term control; gastric bypass $n=150$ year $1, n=137$ year 2, $n=134$ at long-term control; sleeve gastrectomy $n=87$ year 1, $n=76$ year 2, and $n=84$ at long-term control. Statistically significant at level $P<0.02$ with Bonferroni correction $(0.05 / 3)$ weight in three patients (2\%) after GBP and in six (7\%) after SG, $P=0.08$, and from operation weight $10(7 \%)$ and 11 (13\%), $P=0.15$, respectively. At long-term follow-up, weight

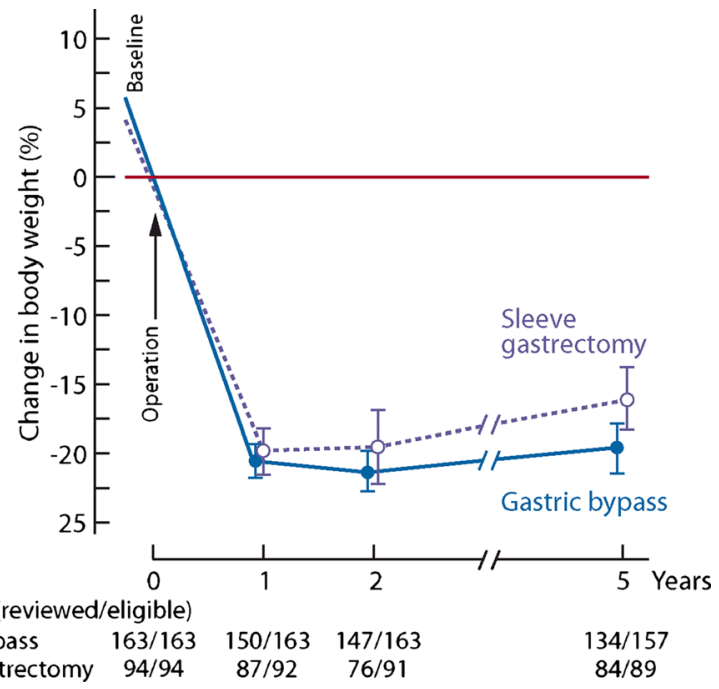

Fig. 1 Mean $( \pm$ SEM) percentage change in body weight from baseline (screening) to long-term follow-up loss was greater in the GBP group (median $23.0 \%$ ) compared with the SG group (median 20.2\%), $P=0.006$, and the percentage of patients who achieved weight losses of 10 or $20 \%$ was higher after GBP than after SG. However, similar percentage of patients in both groups achieved $30 \%$ weight losses on long term (Table 3).

\section{Effect of Preoperative Binge Eating on Weight Loss}

Preoperative BES score did not correlate with the weight loss percent of baseline weight of all patients at year one $(r=0.028,95 \%$ confidence interval (CI) $-0.102-0.175$, $P=0.69)$, year two $(r=0.014,95 \% \mathrm{CI}-0.127-0.155$, $P=0.84)$, or at long term $(r=-0.035,95 \% \mathrm{CI}-0.172-$ $0.108, P=0.63$; Fig. 2). Correlations were similar between BES score and postoperative weight loss (data not shown). In neither of the surgical groups (GBP or SG), correlation was found between BES score and weight loss at year one, year two, or at long term (data not shown). BES score did not correlate with preoperative weight loss, $r=-0.11, P=0.10$. 
Table 3 Number (\%) of patients in both interventions who lost $\geq 10$, $\geq 20$, and $\geq 30 \%$ of baseline weight at long-term follow-up

\begin{tabular}{lll}
\hline Weight loss criterion & $\begin{array}{l}\text { Long-term } \\
\text { follow-up }\end{array}$ & $\begin{array}{l}P \text { between } \\
\text { operations }\end{array}$ \\
\hline$\geq 10 \%$ & & \\
$\quad$ Gastric bypass & $127(95)$ & 0.005 \\
$\quad$ Sleeve gastrectomy & $69(82)$ & \\
$\geq 20 \%$ & & 0.03 \\
$\quad$ Gastric bypass & $87(65)$ & \\
Sleeve gastrectomy & $42(50)$ & 0.41 \\
$\geq 30 \%$ & $33(25)$ & \\
$\quad$ Gastric bypass & $16(19)$ & \\
Sleeve gastrectomy & & \\
\hline
\end{tabular}

Predictors of Postoperative Weight Loss Tables 4 and 5 show the results for univariate and multivariate regression analyses with postoperative weight loss percent at 2-year and long-term control as the dependent variable. At 2-year control, multivariable analysis showed that larger preoperative weight loss was a significant, negative predictor of postoperative weight loss. At long-term control, multivariable analysis indicated that SG predicted less postoperative weight loss and there was a trend $(P=0.05)$ of larger preoperative weight loss to predict less postoperative weight loss.

\section{Discussion}

In this study of 257 patients, we demonstrated median $23 \%$ weight loss 5 years after GBP and $20.2 \%$ after SG, BMI losses being 11.6 and 9.2 and EWL being 46.9 and $43 \%$, respectively. Together, $65 \%$ of patients after GBP and $42 \%$ after SG had over $20 \%$ weight losses 5 years postoperatively. Previously, 6-year outcome after GBP was reported by Adams et al. [20] with mean

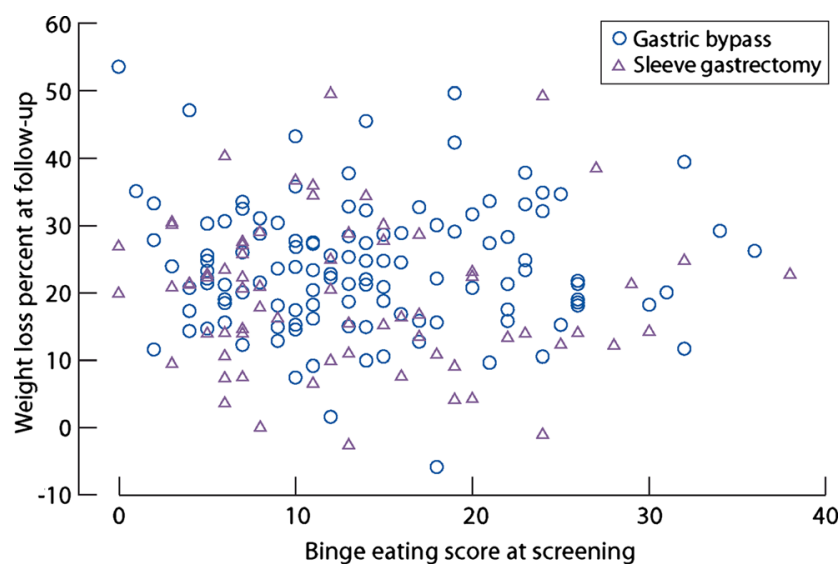

Fig. 2 Relationship between preoperative binge eating score and weight loss percent of baseline weight at long-term follow-up, $r=0.028, P=0.69$
$27.7 \%$ weight loss and BMI change of 12.9 and EWL change of $58 \%$. In the Swedish Obese Subject (SOS) study, weight loss was about $26 \%$ at 6 years with $63 \%$ retention [4]. Our results after GBP are comparable with these long-term studies. Previous systematic reviews have reported better outcome, but they may be optimistic estimates as most report shorter outcome [7] or retention rate in lower [21].

Long-term weight loss studies after SG are few. Kehagias et al. [22] reported 5-year outcome with $77.7 \%$ retention being $57.6 \%$ of EWL in younger and less obese patients compared with our patients. In our non-randomized study, we report slightly poorer long-term outcome after SG compared with GBP. Patients with more severe health problems underwent SG, and this may effect on weight loss. Further studies with long-term follow-up are needed to see if what our study suggests is true and weight loss after SG, as after many other gastric procedures, is poorer than after GBP.

Binge eating behavior preoperatively, measured by BES, did not predict postoperative weight outcome in this study. This is consistent with some previous studies [15], but binge eating has also been associated with impaired [9-11] and improved [12-14] weight losses. Several methods have been used to assess binge eating making comparison across studies difficult. We used BES, which has been considered suitable to measure binge eating behavior [23]. Median scores of our patients were relatively low but range was large. However, we did not find any correlation between BES scores and weight loss. In line with our study, Wadden et al. [24] recently reported that patients with and without binge eating disorder were equally successful in weight loss after bariatric surgery. Our long-term result suggests that for preoperative patient selection purposes, binge eating behavior need not to be assessed.

Preoperative weight loss has been studied as a sign of beneficial behavior change and thus as a predictor of successful weight loss. However, similar to Limbach et al. [25], we found that larger preoperative weight loss predicted less postoperative weight loss. Systematic review by Livhits et al. [8] reported mixed results; seven studies showed a positive association between preoperative and postoperative weight losses, six reported no correlation, and one found negative association. These studies differ in length of follow-up, and this may partly explain discrepancies. At our long-term control, this negative association between preoperative and postoperative weight losses was marginally significant. One explanation may be that among those who started to lose weight prior surgery, weight loss leveled off earlier postoperatively. Based on our results, preoperative weight loss, by itself, is not suitable to select patients for and predict success after bariatric surgery. Still, further research is urgently needed to understand difficulties with weight loss maintenance after bariatric surgery. 
Table 4 Results of univariate regression analysis to predict postoperative weight loss success (\% weight loss) at 2-year and long-term control

\begin{tabular}{|c|c|c|c|c|c|c|}
\hline \multirow[t]{2}{*}{ Variable } & \multicolumn{3}{|c|}{ Two-year control } & \multicolumn{3}{|c|}{ Long-term control } \\
\hline & Beta & $95 \% \mathrm{CI}$ & $P$ & Beta & $95 \% \mathrm{CI}$ & $P$ \\
\hline Age ( $>45$ vs $<45$ years $)$ & -2.71 & $-5.37,-0.05$ & 0.046 & -2.73 & $-5.55,0.09$ & 0.057 \\
\hline Sex (women vs men) & 0.19 & $-2.57,2.95$ & 0.893 & 0.46 & $-2.51,3.44$ & 0.761 \\
\hline Operation (SG vs GBP) & -1.92 & $-4.70,0.86$ & 0.176 & -3.49 & $-6.33,-0.64$ & 0.016 \\
\hline Comorbidities (yes vs no) & -4.40 & $-9.5,0.71$ & 0.091 & -2.18 & $-7.15,-2.80$ & 0.391 \\
\hline Working status (yes vs no) & -0.77 & $-3.96,2.41$ & 0.635 & -0.57 & $-3.95,2.81$ & 0.741 \\
\hline Preoperative weight loss percent & -0.29 & $-0.53,-0.05$ & 0.018 & -0.19 & $-0.45,0.07$ & 0.152 \\
\hline Weight $(<125,125-140,140-160$, and $>160 \mathrm{~kg})$ & 0.43 & $-0.74,-1.60$ & 0.470 & 0.79 & $-0.43,2.02$ & 0.205 \\
\hline Baseline weight $(\mathrm{kg})$ & 0.01 & $-0.04,0.06$ & 0.610 & 0.02 & $-0.03,0.08$ & 0.392 \\
\hline BES score $(>27$ vs $<27)$ & 0.65 & $-5.47,6.76$ & 0.836 & 1.44 & $-4.66,7.54$ & 0.644 \\
\hline BES score $(17-27$ vs $<17)$ & 1.49 & $-1.74,4.72$ & 0.366 & 0.22 & $-3.18,3.62$ & 0.898 \\
\hline BMI at baseline $\left(\mathrm{kg} / \mathrm{m}^{2}\right)$ & 0.15 & $-0.04,0.34$ & 0.129 & 0.16 & $-0.04,0.35$ & 0.110 \\
\hline
\end{tabular}

$C I$ confidence interval, $S G$ sleeve gastrectomy, GBP gastric bypass, $B E S$ binge eating scale

Partial regain of the lost weight in this study is consistent with previous long-term bariatric studies. We did not examine weight-related behaviors, but according to Bond et al. [26], behaviors that are needed to maintain large weight losses after bariatric surgery are similar to those needed after non-surgical weight loss. In the SOS study, one third of the lost weight was regained within 5 years, and this was related to difficulties to follow postoperative diet and decreasing amount of exercise [4]. Loss of control over eating and grazing postoperatively has also been related to poorer weight loss outcome [27]. Further, tendency of the postobese persons to regain weight has been attributed to homeostatic processes that compete against weight loss maintenance [28-30]. Moreover, neuroreceptor alterations following bariatric surgery have been described revealing link between the neuroreceptor system and overeating [31]. Clearly, more research is needed to understand weight regain following large weight losses.

The strengths of this study include high number of patients, real-life clinical setting, long follow-up, and low attrition. The present study has also limitations including lack of randomized design and being a one center study. Long-term weight data was partly self-reported. However, we added $2 \mathrm{~kg}$ to this in order to correct for the tendency for obese persons to underreport their weight [18]. Good correlation with reported and measured weights has been reported recently in patients after bariatric surgery [32].

In conclusion, severe and morbid obesity poses a high risk to health and life expectancy. In this pragmatic study, most patients who underwent GBP or SG maintained 5-year weight loss that is likely to improve their health and quality of life. Variance in weight loss outcome was large and difficult to predict preoperatively. Further research is needed to permit firm estimate about true value of SG in long-term weight maintenance. Future research is also needed to better understand postoperative weight regain and to find methods to prevent it.

\section{Compliance with Ethical Standards}

Conflict of Interest The authors declare that they have no conflict of interest.

Statement of Human Rights This study protocol was approved by the Ethics Committee of Helsinki University Hospital and performed in compliance with the Declaration of Helsinki. All procedures were performed
Table 5 Results of multivariable regression analysis to predict postoperative weight loss success (\% weight loss) at 2-year and long-term control

\begin{tabular}{|c|c|c|c|c|c|c|}
\hline \multirow[t]{2}{*}{ Variable } & \multicolumn{3}{|c|}{ Two-year control } & \multicolumn{3}{|c|}{ Long-term control } \\
\hline & Beta & $95 \% \mathrm{CI}$ & $P$ & Beta & $95 \% \mathrm{CI}$ & $P$ \\
\hline Age ( $>45$ vs $<45$ years $)$ & -1.76 & $1.23,-4.81$ & 0.221 & -2.16 & $0.86,-5.03$ & 0.15 \\
\hline Comorbidities (yes vs no) & -4.76 & $0.20,-10.2$ & 0.058 & -2.18 & $3.41,-7.68$ & 0.44 \\
\hline Operation (SG vs GBP) & -2.31 & $0.59,-5.15$ & 0.123 & -3.67 & $-0.86,-6.60$ & 0.01 \\
\hline Preoperative weight loss percent & -0.37 & $-0.59,-0.14$ & 0.001 & -0.25 & $-0.51,-0.02$ & 0.05 \\
\hline BMI at baseline $\left(\mathrm{kg} / \mathrm{m}^{2}\right)$ & 0.20 & $-0.01,0.43$ & 0.076 & 0.18 & $-0.04,0.45$ & 0.12 \\
\hline
\end{tabular}

$C I$ confidence interval, $S G$ sleeve gastrectomy, $G B P$ gastric bypass 
in accordance with the ethical standards of the regional research committee and with the 1964 Helsinki declaration and its later amendments or comparable ethical standards.

Informed Consent Informed consent was obtained from all individual participants included in the study.

\section{References}

1. Lahti-Koski M, Seppanen-Nuijten E, Mannisto S, et al. Twentyyear changes in the prevalence of obesity among Finnish adults. Obes Rev. 2010;11(3):171-6.

2. Swinburn BA, Sacks G, Hall KD, et al. The global obesity pandemic: shaped by global drivers and local environments. Lancet. 2011;378(9793):804-14.

3. Finkelstein EA, Khavjou OA, Thompson H, et al. Obesity and severe obesity forecasts through 2030. Am J Prev Med. 2012;42(6):563-70.

4. Sjostrom L, Lindroos AK, Peltonen M, et al. Lifestyle, diabetes, and cardiovascular risk factors 10 years after bariatric surgery. N Engl J Med. 2004;351(26):2683-93.

5. Carlsson LM, Peltonen M, Ahlin S, et al. Bariatric surgery and prevention of type 2 diabetes in Swedish obese subjects. N Engl J Med. 2012;367(8):695-704

6. Karlsson J, Taft C, Ryden A, et al. Ten-year trends in health-related quality of life after surgical and conventional treatment for severe obesity: the SOS intervention study. Int J Obes. 2007;31(8):1248-61.

7. Puzziferri N, 3rd Roshek TB, Mayo HG, et al. Long-term follow-up after bariatric surgery: a systematic review. JAMA. 2014;312(9): 934-42.

8. Livhits M, Mercado C, Yermilov I, et al. Preoperative predictors of weight loss following bariatric surgery: systematic review. Obes Surg. 2012;22(1):70-89.

9. Green AE, Dymek-Valentine M, Pytluk S, et al. Psychosocial outcome of gastric bypass surgery for patients with and without binge eating. Obes Surg. 2004;14(7):975-85.

10. Sallet PC, Sallet JA, Dixon JB, et al. Eating behavior as a prognostic factor for weight loss after gastric bypass. Obes Surg. 2007;17(4): 445-51.

11. Scholtz S, Bidlake L, Morgan J, et al. Long-term outcomes following laparoscopic adjustable gastric banding: postoperative psychological sequelae predict outcome at 5-year follow-up. Obes Surg. 2007;17(9):1220-5.

12. Boan J, Kolotkin RL, Westman EC, et al. Binge eating, quality of life and physical activity improve after Roux-en-Y gastric bypass for morbid obesity. Obes Surg. 2004;14(3):341-8.

13. Latner JD, Wetzler S, Goodman ER, et al. Gastric bypass in a lowincome, inner-city population: eating disturbances and weight loss. Obes Res. 2004;12(6):956-61.

14. Malone M, Alger-Mayer S. Binge status and quality of life after gastric bypass surgery: a one-year study. Obes Res. 2004;12(3): 473-81.

15. Powers PS, Perez A, Boyd F, et al. Eating pathology before and after bariatric surgery: a prospective study. Int J Eat Disord. 1999;25(3):293-300.
16. Mechanick JI, Kushner RF, Sugerman HJ, et al. American Association of Clinical Endocrinologists, The Obesity Society, and American Society for Metabolic \& Bariatric Surgery medical guidelines for clinical practice for the perioperative nutritional, metabolic, and nonsurgical support of the bariatric surgery patient. Obesity (Silver Spring). 2009;17 Suppl 1:S1-70.

17. Helmio M, Victorzon M, Ovaska J, et al. Comparison of short-term outcome of laparoscopic sleeve gastrectomy and gastric bypass in the treatment of morbid obesity: a prospective randomized controlled multicenter SLEEVEPASS study with 6-month follow-up. Scand J Surg. 2014;103(3):175-81.

18. Tell GS, Jeffery RW, Kramer FM, et al. Can self-reported body weight be used to evaluate long-term follow-up of a weight-loss program? J Am Diet Assoc. 1987;87(9):1198-201.

19. Gormally J, Black S, Daston S, et al. The assessment of binge eating severity among obese persons. Addict Behav. 1982;7(1):47-55.

20. Adams TD, Davidson LE, Litwin SE, et al. Health benefits of gastric bypass surgery after 6 years. JAMA. 2012;308(11):1122-31.

21. Buchwald H, Estok R, Fahrbach K, et al. Weight and type 2 diabetes after bariatric surgery: systematic review and meta-analysis. Am J Med. 2009;122(3):248-56. e5.

22. Kehagias I, Spyropoulos C, Karamanakos S, et al. Efficacy of sleeve gastrectomy as sole procedure in patients with clinically severe obesity $(\mathrm{BMI} \leq 50 \mathrm{~kg} / \mathrm{m}(2))$. Surg Obes Relat Dis. 2013;9(3):363-9.

23. Grupski AE, Hood MM, Hall BJ, et al. Examining the binge eating scale in screening for binge eating disorder in bariatric surgery candidates. Obes Surg. 2013;23(1):1-6.

24. Wadden TA, Faulconbridge LF, Jones-Corneille LR, et al. Binge eating disorder and the outcome of bariatric surgery at one year: a prospective, observational study. Obesity (Silver Spring). $2011 ; 19(6): 1220-8$.

25. Limbach KE, Ashton K, Merrell J, et al. Relative contribution of modifiable versus non-modifiable factors as predictors of racial variance in roux-en-Y gastric bypass weight loss outcomes. Obes Surg. 2014;24(8):1379-85.

26. Bond DS, Phelan S, Leahey TM, et al. Weight-loss maintenance in successful weight losers: surgical vs non-surgical methods. Int J Obes. 2009;33(1):173-80.

27. Colles SL, Dixon JB, O'Brien PE. Grazing and loss of control related to eating: two high-risk factors following bariatric surgery. Obesity (Silver Spring). 2008;16(3):615-22.

28. Bobbioni-Harsch E, Morel P, Huber O, et al. Energy economy hampers body weight loss after gastric bypass. J Clin Endocrinol Metab. 2000;85(12):4695-700.

29. Schutz Y, Tremblay A, Weinsier RL, et al. Role of fat oxidation in the long-term stabilization of body weight in obese women. Am J Clin Nutr. 1992;55(3):670-4.

30. Galtier F, Farret A, Verdier R, et al. Resting energy expenditure and fuel metabolism following laparoscopic adjustable gastric banding in severely obese women: relationships with excess weight lost. Int J Obes. 2006;30(7):1104-10.

31. Karlsson HK, Tuulari JJ, Tuominen L, et al. Weight loss after bariatric surgery normalizes brain opioid receptors in morbid obesity. Molecular Psychiatry. 2015 Oct online publication.

32. Christian NJ, King WC, Yanovski SZ, et al. Validity of selfreported weights following bariatric surgery. JAMA. 2013;310(22):2454-6. 